\title{
Correction to: Specificity of resistance and geographic patterns of virulence in a vertebrate hostparasite system
}

Agnes Piecyk ${ }^{1,2^{*}}$, Olivia Roth ${ }^{2}$ and Martin Kalbe ${ }^{1 \wedge}$

\section{Correction to: BMC Evol Biol}

https://doi.org/10.1186/s12862-019-1406-3

After publication of the original article [1], the authors have notified us that the incorrect version of Fig. 4 was used. Below you can find the both incorrect and correct versions of the figure.

The original article has been corrected.

Received: 3 April 2019 Accepted: 3 April 2019

Published online: 13 May 2019

\section{Reference}

1. Piecyk et al. (2019) Specificity of resistance and geographic patterns of virulence in a vertebrate hostparasite system (2019) 19:80: https://doi.org/10. 1186/s12862-019-1406-3.

\footnotetext{
* Correspondence: apiecyk@evolbio.mpg.de

'Deceased

'Department of Evolutionary Ecology, Max Planck Institute for Evolutionary

Biology, August-Thienemann-Straße 2, 24306 Plön, Germany

${ }^{2}$ Marine Evolutionary Ecology, GEOMAR Helmholtz Centre for Ocean

Research Kiel, Düsternbrookerweg 20, 24105 Kiel, Germany
}

(c) The Author(s). 2019 Open Access This article is distributed under the terms of the Creative Commons Attribution 4.0 International License (http://creativecommons.org/licenses/by/4.0/), which permits unrestricted use, distribution, and reproduction in any medium, provided you give appropriate credit to the original author(s) and the source, provide a link to the Creative Commons license, and indicate if changes were made. The Creative Commons Public Domain Dedication waiver (http://creativecommons.org/publicdomain/zero/1.0/) applies to the data made available in this article, unless otherwise stated. 


\section{Corrected figure}
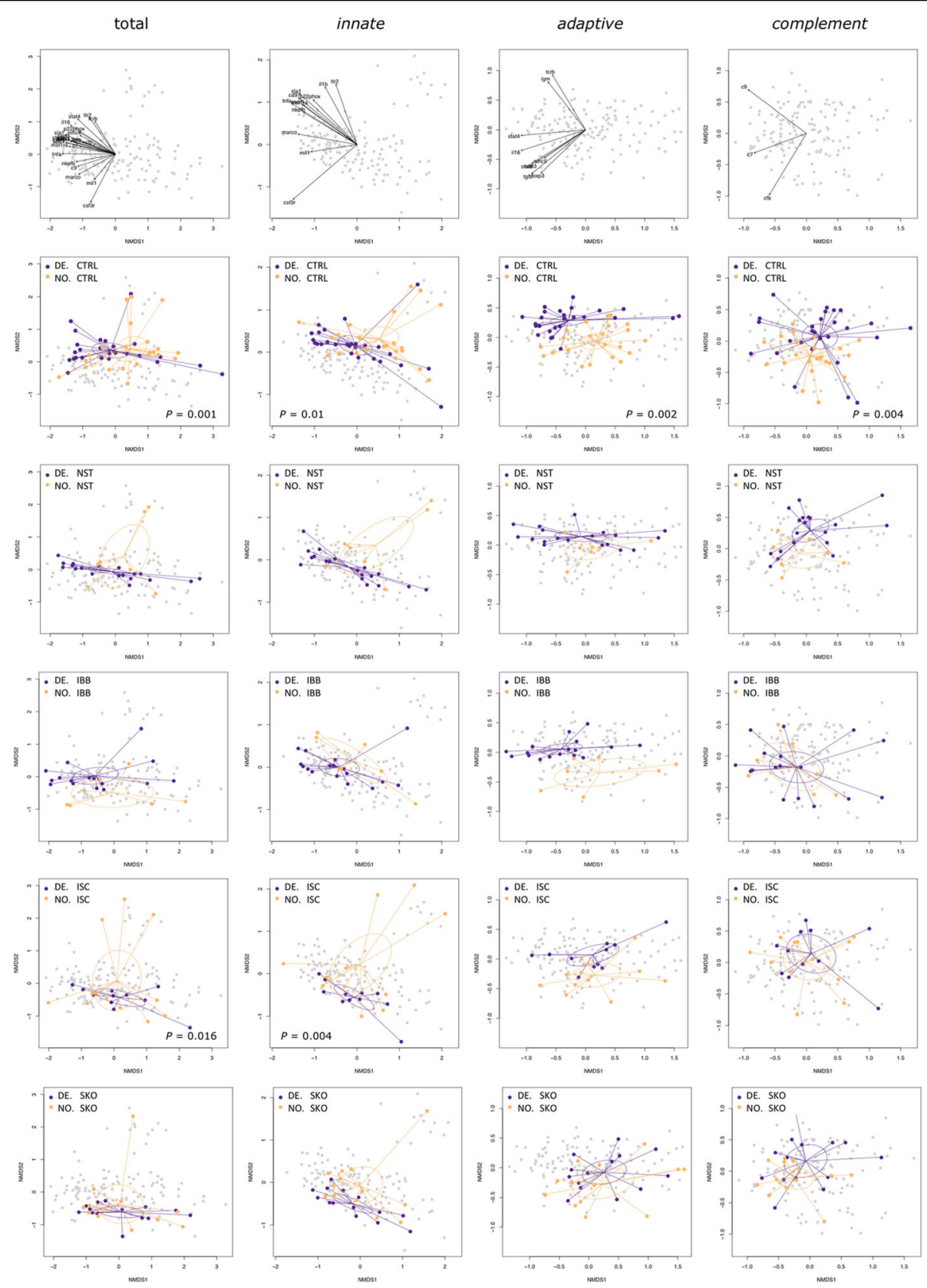

Fig. 4 Multivariate gene expression patterns differ between DE and NO sticklebacks. Non-metric multidimensional scaling (NMDS) plots on Euclidian distances and two dimensions comparing data from NO and DE sticklebacks (contrast 1). NMDS were based on log 10-transformed calibrated normalized relative quantities (CNRQ values) of all 24 immune genes, twelve genes of innate immunity (marco, mst $1 \mathrm{ra}$, mif, il-1 $\beta$, tnfr 1, saal1, tIr2, csf3r, p22 phox , nkef-b, sla1, cd97), nine genes of adaptive immunity (stat4, stat6, igm, cd83, foxp3, tgf- $\beta$, il-16, mhcll, tcr- $\beta$ ), or three genes of the complement system $(c f b, c 7, c 9)$. Each dot represents one individual; colors refer to the host population. Ellipses represent $95 \%$ confidence intervals. $P$-values are shown if significant after FDR-correction. The contribution of each gene is shown in the first row. The second row shows data from sham-exposed (CTRL) sticklebacks. The third to sixth row show data from infected individuals. Function metaMDS() was used to plot the NMDS; the contribution of each gene was plotted by use of the envfit() function (both functions are implemented in R package vegan [74]) 


\section{Incorrect figure}
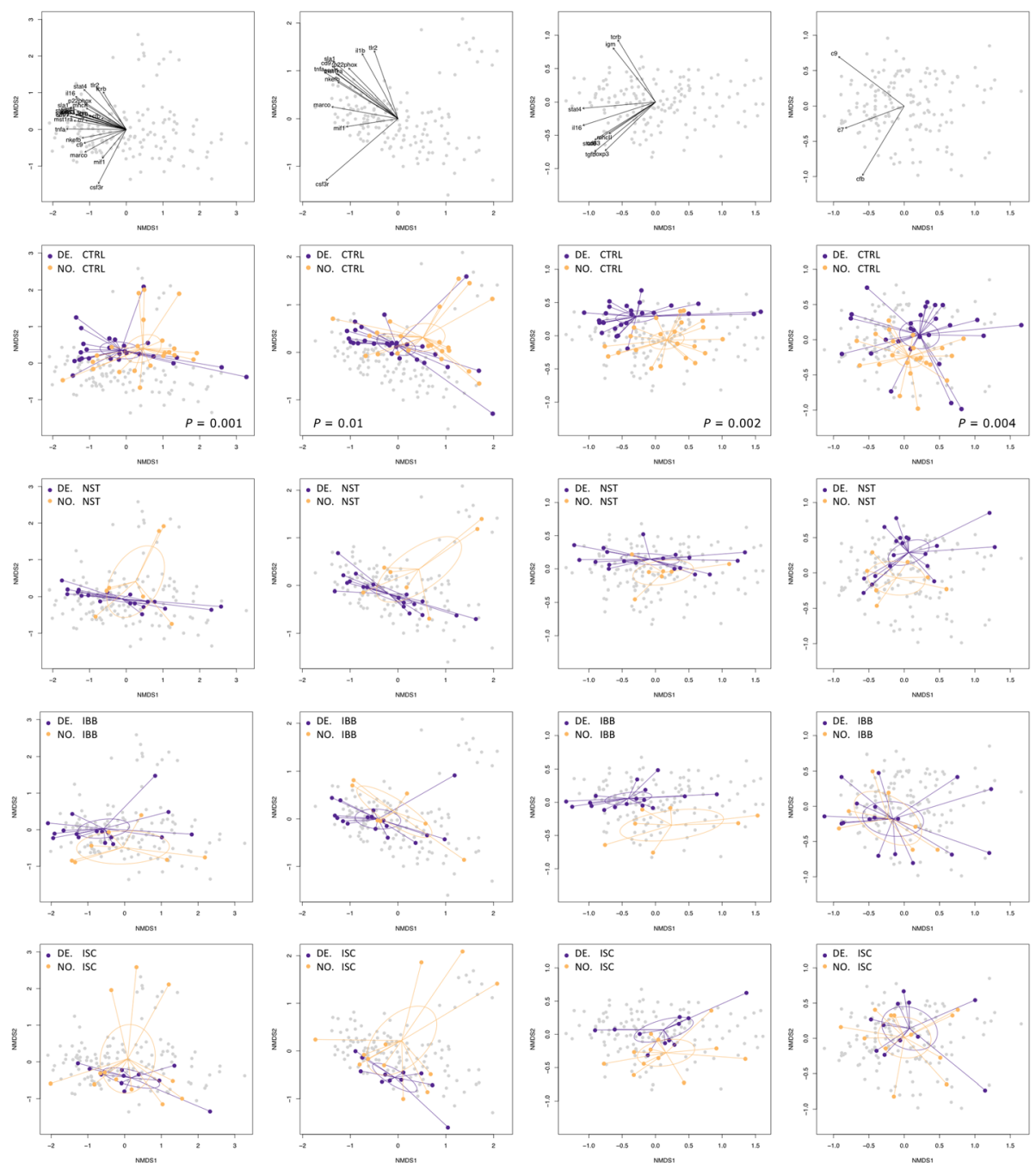

Fig. 4 Multivariate gene expression patterns differ between DE and NO sticklebacks. Non-metric multidimensional scaling (NMDS) plots on Euclidian distances and two dimensions comparing data from NO and DE sticklebacks (contrast 1). NMDS were based on log 10-transformed calibrated normalized relative quantities (CNRQ values) of all 24 immune genes, twelve genes of innate immunity ( $m a r c o, m s t 1 r a, m i f$, il-1 $\beta$, tnfr 1 , saal1, tIr2, csf3r, p22 $2^{\text {phox }}$, nkef-b, sla1, cd97), nine genes of adaptive immunity (stat4, stat6, igm, cd83, foxp3, tgf- $\beta$, il-16, mhcll, tcr- $\beta$ ), or three genes of the complement system $(c f b, c 7, c 9)$. Each dot represents one individual; colors refer to the host population. Ellipses represent $95 \%$ confidence intervals. P-values are shown if significant after FDR-correction. The contribution of each gene is shown in the first row. The second row shows data from sham-exposed (CTRL) sticklebacks. The third to sixth row show data from infected individuals. Function metaMDS() was used to plot the NMDS; the contribution of each gene was plotted by use of the envfit) function (both functions are implemented in R package vegan [74]) 